\title{
Guillermo Orozco y Rodrigo González. Una coartada metodológica: abordajes cualitativos en la investigación en comunicación, medios y audiencias.
}

México: Tintable, 2012. 211 p. ISBN 978-607-95789-0-9

Esta obra plantea preguntas y respuestas que pretenden facilitar el proceso de investigación que se desarrolla en las ciencias sociales y particularmente en los estudios de la comunicación. Los autores realizan en su "coartada metodológica" un ejercicio académico poco común (y muy necesario) entre los textos metodológicos: simplificar algunos de los conceptos más enmarañados y barrocos que se usan en la ciencia y a la vez proponer una estrategia puntual para acercarse y desarrollar con efectividad una investigación científica.

Una coartada metodológica, de Orozco y González, es una apuesta por simplificar el proceso metodológico propio del ámbito académico de la comunicación y las ciencias sociales, y si bien este es un libro dirigido principalmente a los actores del estudio de la comunicación, puede ser tomado por otras disciplinas debido a su capacidad didáctica. En este sentido, este documento se vislumbra (cada vez más) como un referente entre los libros de metodología publicados en los últimos años en el campo de la comunicación, de los medios y de las audiencias.

Los autores utilizan recursos literarios pocas veces vistos en los textos científicos y académicos que hacen de él un texto muy amigable para una múltiple variedad de lectores. Por ejemplo, el uso de una metáfora culinaria (p. 34) es una invitación bastante innovadora y pedagógica para entender las diferencias entre conceptos como: método, técnicas y herramientas de investigación.

A lo largo del libro es posible encontrar las voces (de los autores) combinadas de una manera muy sutil que llevan al lector al salón de clases y participar de una conversación amena y agradable. Guillermo Orozco, doctor en Educación por la Universidad de Harvard y catedrático en la Universidad de Guadalajara, es un consagrado investigador de la comunicación que ofrece muchos años de experiencia impartiendo clases y cátedras sobre metodología de la investigación; mientras que el joven investigador Rodrigo González, doctorando en Comunicación por la Universidad Nacional de La Plata y magíster por la Universidad de Guadalajara, inyecta de una forma muy jovial su propia perspectiva de cómo entender los procesos científicos y los recursos tecnológicos disponibles para enriquecer y facilitar la experiencia de investigación.

Si bien este volumen no es un manual, puede funcionar como tal puesto que propone en forma muy precisa conceptos, nociones y procedimientos muchas veces alejados de la realidad investigada 
o de los escenarios en que se realizan investigaciones en América Latina. Uno de los ejes que guían la propuesta - es decir, la coartada - es hacer una distinción entre los paradigmas científicos que han guiado la producción y la generación de conocimiento académico.

Este libro hace esfuerzos notables en la flexibilización de los conceptos y supone un aporte loable a la idea de una metodología cualitativa en comunicación, aún en construcción. Además otorga respuestas y argumentos sólidos a los cuestionamientos de tipo epistemológico que se hacen a disciplinas relativamente nuevas (como el estudio de la comunicación), al mismo tiempo que da validez a algunos de sus métodos para obtener conocimiento.

El carácter didáctico del texto es muy evidente en sus primeros dos capítulos donde se asume de entrada que el lector puede llegar con algunos o nulos conocimientos de metodología. En los capítulos tres, cuatro y cinco es posible advertir referencias teóricas trascendentales en el desarrollo de todo trabajo de investigación, tales como las perspectivas cualitativas en el estudio de la comunicación, medios y audiencias, y los paradigmas en la producción de conocimientos, así como el papel que tiene el investigador en los procesos metodológicos y de toma de decisiones.

Para el capítulo seis se advierte la “coartada" metodológica propuesta por los autores, que se centra en la abducción, la cual combina tres ingredientes: la inferencia abductiva, la teoría fundada y la perspectiva indicial.

Pensamos que uno de los principales méritos de esta obra es ofrecer al lector una perspectiva dinámica $\mathrm{y}$ flexible sobre el proceso de investigación. Implícitamente la narrativa del texto pone en duda, la (muchas veces) anquilosada forma de comunicar los aspectos metodológicos de la investigación científica. Definitivamente esta obra brinda una visión esperanzadora a los nuevos y jóvenes investigadores respecto de cómo es posible hacer de los procesos metodológicos algo novedoso y seductor.

Más allá del carácter académico que persigue el libro, también es posible aventurar su aplicación a la formación de sujetos críticos y competitivos al margen de si serán o no profesionales de la investigación. Con unlenguaje agradabley atractivo logra romper con la acostumbrada solemnidad de los textos académicos, lo cual es un logro ya que implícitamente consigue despojarse de la visión positivista de comprender y hacer ciencia.

En los ambientes educativos cada vez más complejos y fragmentados, este trabajo se presenta como una posibilidad para vincular a los estudiantes (no solo de comunicación) en formas discursivas que van más allá de lo secuencial y lineal, puesto que ofrece claramente una distribución y organización que bien puede emular la lógica hipertextual segmentada y complementaria, en la que es el lector, en último término, el que propone 
un camino a seguir en la lectura a partir de sus propósitos o intereses propios. En este sentido, se puede decir que es un texto que no solamente aventura maneras frescas de entender la investigación sino, además, el proceso metodológico en sí mismo puede y debe ser flexible en un constante ir y venir.

\section{José Manuel Corona Rodríguez}

Centro Universitario de Ciencias Sociales y Humanidades, Universidad de Guadalajara, México

joma_corona@hotmail.com

\section{${ }^{*} A^{*} C$}

